\title{
Firm heterogeneity, comparative advantage and the transfer problem
}

\author{
Federico Trionfetti ${ }^{1}$ \\ Aix-Marseille Univ, CNRS, EHESS, Centrale Marseille, AMSE, France
}

\begin{abstract}
A B S T R A C T
This paper studies the transfer problem in a model featuring comparative advantage, mo- nopolistic competition, trade costs, and firm heterogeneity in factor intensity. The results are very different from those of the previous literature. First, a transfer creates a secondary burden in situations where the neoclassical version of the Heckscher-Ohlin model would not. Second, a transfer affects wage inequality. Third, a transfer is not neutral to world welfare. Fourth, floating exchange rates do not substitute for deflation. Fifth, a simulation

exercise shows that the quantitative effects of trade imbalances are comparable in magni- tude to those arising from major trade agreements.
\end{abstract}

\section{Introduction}

"After the First World War economists discussed the effects of a unilateral transfer - such as reparations - on the terms of trade. And in the 1950s, as the end of the Marshall Plan comes into sight, economists must once again consider an identical analytic problem - the possible effects of a cessation of unrequited imports on the terms of trade". ${ }^{2}$ In the XXI century we are confronted with analytically similar problems arising from transfers of various sorts; such as those arising from trade imbalances, from the intra-European transfers, from foreign aid, and remittances. Some of these transfers arise from governmental decisions (e.g., intra European Union transfers and foreign aid), some are the results of private decisions (remittances), some are the results of inter-temporal optimisation (e.g., trade imbalances) but all can be studied from the point of view of the impact they have on the economies concerned. A transfer has two possible effects. One is the primary effect, or primary burden, which consists in the resources to be transferred. The other is the secondary effect, or secondary burden, which consists in the general equilibrium repercussions of the transfer on welfare. ${ }^{3}$ The existence of a primary burden is, of course, incontrovertible while the existence and magnitude of the secondary burden has been the object of contention in the entire literature on the Transfer Problem. As is well known, the controversy over the secondary burden has been sparked off by Keynes (1929) who found remarkable commentators in Ohlin (1929) and Rueff (1929). The literature

E-mail address: Federico.Trionfetti@univ-amu.fr

1 This paper is part of a research project funded by the Agence Nationale de la Recherche (France). Grant number ANR-12-GLOB-0005-01. I thank Vera Danilina for first class research assistance. I thank my department - Aix-Marseille School of Economics - for research funds that helped me carry out the simulation part of the project.

2 Samuelson (1952, p. 278).

3 Keynes (1929) uses the term 'Budgetary Problem' to refer to the primary effect and 'Transfer Problem' to refer to the secondary effect. Samuelson (1952) uses the terms 'primary burden' and 'secondary burden'. 
flourished with contributions by Pigou (1932), and Metzler (1942, 1951). This literature examined the possible repercussions of a transfer on the donor terms of trade. Some argued that the donor terms of trade would deteriorate thus giving rise to a secondary burden for the donor (this view became known as the orthodox view), some argued that the donor terms of trade might actually improve thus giving rise to a secondary benefit for the donor (the so called anti-orthodox view), and some argued that the transfer would be neutral on the terms of trade. Samuelson $(1952,1954)$ marked a milestone in the literature when he came to clarify the conditions under which the orthodox or anti-orthodox view is right. Later works took into account additional aspects such as the link between stability and the terms of trade effects of transfers (Johnson, 1956; Mundell, 1960; Galor and Polemarchakis, 1987), non-traded goods (McDougall, 1965; Dornbusch et al., 1977a), multiple countries (Dixit, 1983; Yano 1983), many goods (Balasko 1978), non-identical preference and non-traded goods (Jones, 1970, 1975), investment-induced terms of trade effects (Djajić et al., 1999). Though the model assumptions became richer the attention remained concentrated on the terms of trade effects of transfers. The focus on the terms of trade was natural and well placed since the conceptual framework used by all this literature was the one we now call the "neoclassical model" of trade. In this model, the only possible way a transfer creates a secondary burden is via an adverse change in the terms of trade. Samuelson makes this point very clearly in his two famous articles $(1952,1954)$.

I re-examine the Transfer Problem in the light of models featuring factor proportions, monopolistic competition and heterogeneity in firm factor intensity. Using this model I study the effect of a transfer on productivity, income distribution and factor allocation. Interestingly, the importance of such re-examination had not escaped Samuelson's crisp analysis when he wrote: "Only if one brings in Chamberlinian phenomena of monopolistic competition do substantive effects arise, ..." Samuelson (1954, p. 288). This line of research was not pursued by Samuelson and remained almost entirely unexplored even after the appearance and vast utilisation of monopolistic competition models in international trade theory.

Only a few papers took this research direction. Brakman and van Marrewijk (1995) were the first to use a model of monopolistic competition to study the effect of transfers in the form of aid to developing countries. The key elements in their model are non-identical preferences between countries and home biased expenditure. Their model is a single-factor, homogeneous firms, free trade model not suitable to study the matters I address in this paper. Corsetti et al. (2013) use a model of monopolistic competition, heterogeneous firms, and a partition of all firms in exporters and non-exporters. This partition allows them to distinguish between the intensive and extensive margin of trade as channels through which a transfer may affect welfare. They find that the presence of the extensive margin attenuates the repercussions of the transfer on the real exchange rate and on the terms of trade. This is because part of the demand changes induced by the transfer are absorbed by the extensive margin. Their approach differs from mine especially because they focus on the terms of trade while I study the effects of transfers also on inequality, productivity, relative price of goods, and the exchange rate. As a result of different research focuses, their model differs from mine in that it assumes no comparative advantage, no selection into entry, unbiased heterogeneity, and a partition between exporting and non-exporting firms that I dispose of since it is not necessary for my purposes. Epifani and Gancia (2017) use a multi-country, two-sector, one-factor model of monopolistic competition where, like in Davis (1998), the homogeneous good is non traded and where they insert intermediate inputs in the same way as in Krugman and Venables (1995). In their model a trade surplus may bring about an appreciation of the exchange rate, a terms-of-trade improvement and a welfare increase. The key elements of their model are intermediate inputs and trade cost in the homogeneous good. Their model differs from mine especially because it does not include comparative advantage and heterogeneous firms; as such it is unsuitable to study the issues related to productivity and the skill premium that I address in my study. Picard and Worrall (2015) also study the effects of transfers. They study whether the possibility of transfers between countries make the case for a currency area stronger or weaker. Their numerical simulations show that a currency area is optimal under reasonable parametrisation of the model. Their work, like mine, considers transfers and alternative exchange rate regimes but differs from mine in the research objective and in the model structure. Their singlefactor, monopolistic competition model suffices to their purposes but does not take on board many elements I instead have to consider, such as factor proportions and firm heterogeneity. A few other papers are very close to mine in terms of the model but are quite different in terms of the research objective. Bernard et al. (2007), Burstein and Vogel (2016); Costinot and Vogel (2010) and Crozet and Trionfetti (2013) all use heterogeneous firms and comparative advantage. However, differently from the present paper, the first paper does not allow for heterogeneity in factor intensity at firm level, the second does not allow for entry, the third and fourth are more closely related but they do not contain flexible exchange rates. Most of all, the difference with these four papers is in the research objective since none of them studies the the transfer problem. The empirical literature counts only three papers. Devereux and Smith (2007) provide an empirical study on the effects of Franco-Prussian reparation payments. Lane and Milesi-Ferretti (2004) provide evidence that countries with net external liabilities tend to have depreciated real exchange rates. Crinò and Epifani (2014) augment the (Dornbusch et al., 1977b) model with a non-traded good and find, consistently with such model, that a trade surplus (a transfer) is associated with lower skill-intensity of donor exports when the donor is skill-abundant and a higher skill-intensity of donor exports when the donor is skill-scarce. ${ }^{4}$

The results of my study contrast sharply with those of the previous literature on the transfer problem. I find that a transfer brings about adjustments in the terms of trade, in the degree of specialisation, in the skill premium, and in welfare even in situations where the previous literature found that a transfer is neutral on the equilibrium. All these effects are

\footnotetext{
${ }^{4}$ Incidentally, as I will discuss below, their result is consistent with my model.
} 
due, for the most part, to product differentiation, comparative advantage and trade costs. Heterogeneity in factor intensity is responsible for changes on average productivity whose sign depends on the relative factor abundance of the donor. Furthermore, while in the previous literature a transfer is neutral on world welfare, in my model it is not because transfer-induced productivity changes affect world welfare. I address the issue of flexible versus fixed exchange rate. In the early literature it was suggested that a freely floating exchange rate would eliminate the effect of a transfer on nominal wages. I find that in the presence of comparative advantage such conclusion is incorrect. To eliminate the fall in nominal wage it is necessary to expand the money supply in the donor country. Lastly, I calibrate the model and simulate the elimination of trade imbalances between the U.S., the Euro Area and China. I find a secondary burden for the deficit-donor countries and a secondary benefit for the (only) surplus-recipient country (China). The overall welfare effects are found to be comparable in magnitude to those of major trade agreements.

To sum up, the highlights of the model are product differentiation, comparative advantage and heterogeneity in factor intensity. The highlights of the research objective are the consequences of transfers on the skill-premium, productivity, and world welfare. The model is also able to shed new light on the old questions of devaluation versus deflation. Lastly, it provides a quantification of the effects of eliminating trade imbalances.

The remainder of the paper is as follows: Section 2 lays out the model, Section 3 discusses the general equilibrium and welfare effects of transfers, Section 4 revisits the deflation versus devaluation debate, Section 5 performs a simulation exercise, Section 6 concludes and the appendix Section 7 completes the paper.

\section{The model}

The world economy is composed of two countries, indexed by $c=A, B$; endowed with two factors, indexed by $j=H, L$; which produce two differentiated goods, indexed by $i=Y, Z .^{5}$ Each country is endowed with a positive share $v_{j}^{c}$ of the world's endowments denoted $\underline{H}$ and $\underline{L}$. For convenience, very often I will refer to $H$ as skilled labour and to $L$ as unskilled labour. International trade is subject to iceberg trade costs by which for one unit of good shipped only a fraction $\tau \in[0,1]$ arrives at its destination.

Technology. Production requires fixed and variable inputs in each period. The variable input technology takes the CES form here represented by the marginal cost which, for a firm in industry $i$ of country $c$, is

$$
m c_{i}^{c}(\xi)=\left\{\left(\lambda_{i}\right)^{\sigma}\left(w_{L}^{c}\right)^{1-\sigma}[l(\xi)]^{\sigma-1}+\left(1-\lambda_{i}\right)^{\sigma}\left(w_{H}^{c}\right)^{1-\sigma}[h(\xi)]^{\sigma-1}\right\}^{\frac{1}{1-\sigma}}
$$

where $\lambda_{i} \in(0,1)$ is a constant technology parameter of industry $i$, the variables $w_{H}^{c}$ and $w_{L}^{c}$ denote, respectively, the price of $H$ and $L$ in country $c$, and $\sigma \neq 1$ measures the elasticity of substitution between factors. The variable $\xi$ is a random variable with cumulative distribution $G(\xi)$ and with support $\left(\xi_{0}, \infty\right)$ where $\xi_{0}>0$. The continuous, positive, increasing, and differentiable functions $l(\xi)$ and $h(\xi)$ contribute to determining factor productivity. Let $\beta(\xi) \equiv h(\xi) / l(\xi)$ be monotonic. I will say that heterogeneity is $H$-biased if $\beta^{\prime}(\xi)>0$; is L-biased if $\beta^{\prime}(\xi)<0$; is unbiased if $\beta^{\prime}(\xi)=0$.

Firms seeking to enter the market face fixed entry costs. Paying the fixed entry costs gives the right to draw $\xi$. Upon drawing $\xi$ the firm is able to compute its profit. The firm stays in the market if the profit is non-negative and exits otherwise. If the firm stays it remains attached to its value of $\xi$ until death do them part. At any point in time any firm has a probability of death which, to save notation, is set to be equal to $1 .{ }^{6}$ Given that $G(\xi)$ and the probability of death are constant over time, it is irrelevant for the equilibrium whether the firm decides to stay on the basis of expected profit or the basis of current profit. Let $\xi_{i}^{* c}$ be the value of $\xi$ in industry $i$ of country $c$ for which the profit is equal to zero. We may than define the average marginal cost in the industry as $\widetilde{m c} c_{i}^{c} \equiv\left\{\frac{1}{1-G\left(\xi_{i}^{* c}\right)} \int_{\xi_{i}^{*}}^{\infty}\left(m c_{i}^{c}\right)^{1-\sigma} d G\right\}^{\frac{1}{1-\sigma}}$, which may be more conveniently written as

$$
\widetilde{m} c_{i}^{c}=\left[\left(\lambda_{i}\right)^{\sigma}\left(w_{L}^{c}\right)^{1-\sigma}\left(\widetilde{l}_{i}^{c}\right)^{\sigma-1}+\left(1-\lambda_{i}\right)^{\sigma}\left(w_{H}^{c}\right)^{1-\sigma}\left(\tilde{h}_{i}^{c}\right)^{\sigma-1}\right]^{\frac{1}{1-\sigma}} .
$$

where $\tilde{l}_{i}^{c} \equiv\left(\frac{1}{1-G\left(\xi_{i}^{* c}\right)} \int_{\xi_{i}^{* c}}^{\infty}(l(\xi))^{\sigma-1} d G\right)^{\frac{1}{\sigma-1}}$ and analogously for $\widetilde{h}_{i}^{c}$. This definition will be used several times below.

Coming to fixed costs we may assume that they are homogenous or heterogenous across firms. These alternative assumptions give qualitatively the same results. I assume homogeneous fixed costs since this assumption allows to be focused on heterogeneity in the production process (which is the heart of the matter). Incidentally, this is the assumption most commonly adopted in the literature (Melitz, 2003; Bernard et al., 2007; and many others). Specifically, I represent the fixed input as a homogenous, non-traded, composite good produced in a perfectly competitive market by assembling in a CES all the varieties of the domestic industry output. Accordingly, the cost of producing one unit of fixed input coincides with the average marginal cost described in (2). Thus, the fixed production cost is $\digamma \widetilde{m c}{ }_{i}^{c}$ where $\digamma$ is a positive constant; the fixed entry cost is $\digamma_{e} \widetilde{m c}_{i}^{c}$ where $\digamma_{e}$ is a positive constant. This specification is inspired by Ethier (1980) but it may also be interpreted as in Yeaple (2005), who assumes that the fixed cost is represented by output that must be produced by the firm and

\footnotetext{
${ }^{5}$ Product differentiation is based on Dixit-Stiglitz monopolistic competition but the economic mechanism it carries would remain unchanged if we used other forms of product differentiations such as those à la Armington (1969) or Eaton and Kortum (2002).

${ }^{6}$ Setting such probability to 1 means that the equilibrium is renewed at every instant.
} 
that ultimately cannot be sold. The difference with Yeaple (2005) is that in the present model the unit cost function of unsaleable output is $\widetilde{m c}_{i}^{c}$. Fixed costs are proportional to the average marginal cost. A convenient simplification obtained from modelling fixed costs in this way is that the average factor intensity in the industry is independent of aggregate industry output.

Demand. The representative consumer has preferences represented by the Cobb-Douglas utility function $u=(Y)^{\gamma_{Y}}(Z)^{\gamma_{Z}}$ where $\gamma_{i} \in(0,1), \gamma_{Y}+\gamma_{Z}=1$ and where $Y$ and $Z$ are CES aggregates whose elasticity of substitution between varieties is $\varsigma>1$. Gross domestic product is $I^{c}=w_{L}^{c} v_{L}^{c} \underline{L}+w_{H}^{c} v_{H}^{c} \underline{H}$. Factors of production are taxed for the sole purpose of raising the resources to be transferred. I assume per-capita taxation so as to rule out any direct distributional consequence of the transfer. Let $e$ represents the units of $A$ 's currency needed to purchase one unit of $B$ 's currency. Let $T$ be the transfer from $A$ to $B$ denominated in the currency of $A$. When $T>0$ country $A$ is the donor and $B$ the recipient, vice-versa when $T<0$. National disposable income, equal to expenditure, is then $E^{A}=I^{A}-T$ for country $A$ and $E^{B}=I^{B}+T / e$ for $B$.

The demand emanating from domestic residents, $s_{i d}^{A}$, and from foreign residents, $s_{i x}^{A}$, in local currency for the output of a firm in industry $i$ of country $A$ is:

$$
s_{i d}^{A}(\xi)=\left(\frac{p_{i d}^{A}(\xi)}{P_{i}^{A}}\right)^{1-\varsigma} \gamma_{i} E^{A} \quad s_{i x}^{A}(\xi)=\left(\frac{p_{i x}^{A}(\xi)}{P_{i}^{B}}\right)^{1-\varsigma} \gamma_{i} E^{B},
$$

where $s$ stands for sales, $d$ for domestic, and $x$ for foreign; $p_{i d}^{A}(\xi)$ and $p_{i x}^{A}(\xi)$ are the price faced by consumers and $P_{i}^{c}$ is the price index. All prices are expressed in the currency of the country where they are consumed. Analogous functions obtain for $s_{i d}^{B}$ and $s_{i x}^{B}$. Total firm sales are represented by $s_{i}^{A}(\xi)=s_{i d}^{A}(\xi)+e s_{i x}^{A}(\xi)$ and $s_{i}^{B}(\xi)=s_{i d}^{B}(\xi)+s_{i x}^{B}(\xi) / e$.

Profit maximization and zero profit. With monopolistic competition and under the large-group assumption, the profitmaximising prices for the domestic and the foreign market are:

$$
p_{i d}^{c}(\xi)=\frac{\varsigma}{\varsigma-1} m c_{i}^{c}(\xi), \quad p_{i x}^{A}(\xi)=\frac{p_{i d}^{A}}{e \tau}, \quad p_{i x}^{B}(\xi)=\frac{e p_{i d}^{B}}{\tau}
$$

The notation $m c_{i}^{c}(\xi)$ reminds us that firms with different $\xi$ have different marginal costs; they therefore apply different prices and will have different sales as a result. Indeed, for any two firms with draws $\xi^{\prime}$ and $\xi^{\prime \prime}$ the relative sales are

$$
\frac{s_{i}^{c}\left(\xi^{\prime}\right)}{s_{i}^{c}\left(\xi^{\prime \prime}\right)}=\left[\frac{m c_{i}^{c}\left(\xi^{\prime}\right)}{m c_{i}^{c}\left(\xi^{\prime \prime}\right)}\right]^{1-\varsigma} .
$$

After drawing $\xi$ a firm decides to stay in the market if $\pi_{i}^{c}(\xi)>0$ and decides to quit otherwise. Thus, recalling that the firm's profit may be written as $\pi_{i}^{c}(\xi)=s_{i}^{c}(\xi) / \varsigma-\digamma \widetilde{m c} c_{i}^{c}$, the zero profit condition is ${ }^{7}$

$$
s_{i}^{c}\left(\xi_{i}^{* c}\right)=\varsigma \digamma \widetilde{m c} c_{i}^{c}
$$

Aggregation. Applying Eqs. (5) and (6) to $s_{i}^{c}(\xi) / s_{i}^{c}\left(\xi_{i}^{* c}\right)$ gives the sales of any firm as function of the cut off value $\xi_{i}^{* c}$; that is: $s_{i}^{c}(\xi)=\left[\frac{m c_{i}^{c}(\xi)}{m c_{i}^{c}\left(\xi_{i}^{* c}\right)}\right]^{1-\varsigma} \varsigma \digamma \widetilde{m c} c_{i}^{c}$. From this expression we obtain the average sales defined as $\bar{s}_{i}^{c} \equiv \frac{1}{1-G\left(\xi_{i}^{* c}\right)} \int_{\xi_{i}^{* *}}^{\infty} s_{i}^{c}(\xi) d G$ which, using the above expression for $s_{i}^{c}(\xi)$ turns out to be

$$
\bar{s}_{i}^{c}=\left[\frac{\widetilde{m c}_{i}^{c}}{m c_{i}^{* c}\left(\xi_{i}^{* c}\right)}\right]^{1-\varsigma} \varsigma \digamma \widetilde{m c_{i}^{c}} .
$$

Computing the average profit in industry $i$ of country $c$ we obtain

$$
\bar{\pi}_{i}^{c}=\left[\frac{\bar{s}_{i}^{c}}{\zeta}-\digamma \widetilde{m}_{i}^{c}\right]
$$

Using (4) we may compute the average domestic price, the average export price and the price indices:

$$
\begin{aligned}
& \widetilde{p}_{i d}^{c}=\frac{\varsigma}{\varsigma-1} \widetilde{m c}_{i}^{c}, \quad \widetilde{p}_{i x}^{A}=\frac{\widetilde{p}_{i}^{A}}{e \tau}, \quad \widetilde{p}_{i x}^{B}=\frac{e \widetilde{p}_{i}^{B}}{\tau}, \\
& P_{i}^{A}=\left[M_{i}^{A}\left(\widetilde{p}_{i d}^{A}\right)^{1-\varsigma}+M_{i}^{B}\left(\widetilde{p}_{i x}^{A}\right)^{1-\varsigma}\right]^{\frac{1}{1-\varsigma}}, \\
& P_{i}^{B}=\left[M_{i}^{B}\left(\widetilde{p}_{i d}^{B}\right)^{1-\varsigma}+M_{i}^{A}\left(\widetilde{p}_{i x}^{B}\right)^{1-\varsigma}\right]^{\frac{1}{1-\varsigma}},
\end{aligned}
$$

where $M_{i}^{c}$ is the mass of firms.

\footnotetext{
${ }^{7}$ Since $m c_{i}^{c}(\xi)$ is monotonic in $\xi$ there is one and only one $\xi_{i}^{* c}$.
} 
General Equilibrium. In addition to profit-maximising prices and to the zero profit conditions discussed above, there are five additional sets of equilibrium conditions. First, stationarity of the equilibrium requires the mass of potential entrants, $M_{e i}^{c}$, to be such that at any instant the mass of successful entrants, $\left[1-G\left(\xi_{i}^{* c}\right)\right] M_{e i}^{c}$ equals the mass of incumbent firms who die, $M_{i}^{c}$ :

$$
\left[1-G\left(\xi_{i}^{* c}\right)\right] M_{e i}^{c}=M_{i}^{c} .
$$

Second, free entry ensures that the expected benefit from entry equals the entry cost:

$$
\left[1-G\left(\xi_{i}^{* c}\right)\right] \bar{\pi}_{i}^{c}=\digamma_{e} \widetilde{m c} c_{i}^{c} .
$$

The left-hand-side is the present value - prior to entry - of the expected profit and the right-hand-side is the entry cost.

Third, we need to ensure goods market equilibrium. Computing the average demand from (3) we see that average demand is equivalent to replacing the average price into the demand function, which allows writing the goods market equilibrium equations as

$$
\begin{aligned}
& \bar{s}_{i}^{A}=s_{i d}^{A}\left(\widetilde{p}_{i d}^{A}\right)+e s_{i x}^{A}\left(\widetilde{p}_{i x}^{A}\right), \\
& \bar{s}_{i}^{B}=s_{i d}^{B}\left(\widetilde{p}_{i d}^{B}\right)+s_{i x}^{B}\left(\widetilde{p}_{i x}^{B}\right) / e .
\end{aligned}
$$

Fourth, equilibrium in factor market requires that total factor demand, denoted $L_{i}^{c}$ and $H_{i}^{c}$, be equal to factor supply

$$
\begin{aligned}
& L_{Y}^{c}+L_{Z}^{c}=v_{L}^{c} \underline{\underline{L}}, \\
& H_{Y}^{c}+H_{Z}^{c}=v_{H}^{c} \underline{H} .
\end{aligned}
$$

Lastly, two 'quantitative' money market equations assure that nominal money supply equates nominal money demand. Money supply equals domestic credit, $\mathfrak{M}^{c}$, plus reserves. A transfer $T>0$ depletes reserves in $A$ and increases reserves in $B$. Likewise, mutatis mutandi, for a transfer $T<0$. Thus, money supply is $\mathfrak{M}^{A}-T$ and $\mathfrak{M}^{B}+T / e$. Money is demanded only for transaction purposes and it is therefore equal to disposable income divided by the velocity. I set the velocity to 1 to save notation. A transfer affects money demand because it affects disposable income. The money market equations are: $\mathfrak{M}^{A}-T=I^{A}-T$ and $\mathfrak{M}^{B}+T / e=I^{B}+T / e$ which simplify to

$$
\mathfrak{M}^{A}=I^{A}
$$

$$
\mathfrak{M}^{B}=I^{B} .
$$

After replacing Eqs. (9) and (10)-(8) into (13)-(17) and remembering that each of these is required to hold for any $i$ and any $c$ we can count equations and unknowns for the two regimes of fixed and flexible exchange rate. Fixed Exchange Rate. Setting $e=1$ we count 11 independent equilibrium conditions and 12 endogenous variables. The equations are the four free-entry conditions (13), any three out of the four goods market equilibrium conditions (14) and (15), and the four factor market equilibrium (16) and (17). The endogenous are $\left\{\xi_{i}^{* c}\right\},\left\{w_{I}^{c}, w_{H}^{c}\right\}$ and $\left\{M_{i}^{c}\right\}$. The equilibrium value of all other endogenous variables can be computed from these. In particular under fixed exchange rate the money supply is endogenous and simply adjusts to accommodate any change in money demand. The choice of a numéraire makes the model determined. The fixed exchange rate model is, after all, a pure trade model. Flexible Exchange Rate. Setting $\mathfrak{M}^{A}$ and $\mathfrak{M}^{B}$ equal to exogenous constants and letting $e$ be endogenous we count 13 independent equilibrium conditions and 13 endogenous variables. The equilibrium conditions are the same as in the fixed exchange rate regime plus the two money market equations (18) and (19). The 13 endogenous are the same 12 endogenous as in the fixed exchange rate regime plus the exchange rate $e$.

\section{General equilibrium effects of transfers}

The key elements in the model above are differences in factor proportions, product differentiation, and heterogeneous firms. I will study the role played by each of this elements in giving rise to the effects of a transfer. I will begin, however, by discussing the effect of a transfer in the neoclassical version of the factor proportions model of trade since this will be the benchmark from which our model departs. Throughout this section the exchange rate is fixed to unity.

\subsection{The neoclassical benchmark}

To obtain the neoclassical model from mine all we have to do is to let $Y$ and $Z$ be homogeneous goods, $G(\xi)$ be degenerate so that firms are homogeneous, markets be perfectly competitive, and set all fixed costs to zero. Such neoclassical version gives rise to the following result:

Proposition 1. "Samuelson neutrality proposition". In the neoclassical model of trade with identical Cobb-Douglas preferences a transfer has no impact on any endogenous variable. Therefore, there is no terms of trade effect and there is no secondary burden. 
Proof. See appendix Sect. 7.1.

Samuelson obtains this result first in a model without trade costs (Samuelson 1952) and then in the model with trade costs (Samuelson 1954). ${ }^{8}$ In both cases he obtains the result in a model with fixed output but argues with crystal clear logic that the same result should obtain when output may vary. This intuition is confirmed formally in Mundell's famous paper on the pure theory of international trade (1960, Section 4) where, however, he only proves it for the case of free trade. To complete the picture I prove in appendix Section 7.1 that Proposition 1 is valid also in the case of variable output and costly trade. It is useful to recall here the intuition for Proposition 1. The case of zero trade costs is obvious: in such case consumers face the same price, given identical preferences a transfer has no impact on relative demand for goods and therefore has no impact on the equilibrium. If trade costs are positive consumers in different countries face different prices but the unitary elasticity of substitution makes that the expenditure shares are insensitive to such price differences. Thus, the transfer is neutral also in the presence of trade costs. This will not be the case in the model I propose.

Proposition 1 is an excellent starting point for our study because it ensures that any effect we find when using our model will be due exclusively to its features; namely, product differentiation, biased heterogeneity, and their interactions with factor proportions.

\subsection{Product differentiation and comparative advantage}

We now resume the full model described in Section 2 and study the effect of transfers when product differentiation is in the model. To this purpose I keep the assumption of firm homogeneity, i.e., a degenerate $G(\xi)$. I do not need firm homogeneity to obtain the results but I prefer to discuss firm heterogeneity separately in the next sub-section for clarity of exposition.

By its very nature a transfer reduces expenditure in the donor country and increases it in the recipient country thereby operating an international reallocation of expenditure. Such reallocation may give rise to excesses demand and supply which are the only channels through which a transfer can affect the initial equilibrium. Indeed, the analysis of the transfer problem may be posed as the study of the changes in endogenous variables required to eliminate the excess demand and supply created by the transfer. This is why I begin my analysis by studying the effect of a transfer on the excess demand and supply for any variety. Differentiating Eqs. (14) and (15) with respect to $T$ around $T=0$ gives us the excess demand which I express in percentage changes and denoted $\hat{D}_{i}^{c: 9}$

$$
\begin{aligned}
& \widehat{D}_{i}^{A}=\frac{-\left(1-\theta^{2}\right) M_{i}^{B}\left(\widetilde{p}_{i d}^{B}\right)^{1-\varsigma} d T}{\theta M_{i}^{A}\left(\widetilde{p}_{i d}^{A}\right)^{1-\varsigma}+\left(\theta^{2} \iota^{B}+\iota^{A}\right) M_{i}^{B}\left(\widetilde{p}_{i d}^{B}\right)^{1-\varsigma}} \lessgtr 0 \Leftrightarrow d T \gtrless 0, \\
& \widehat{D}_{i}^{B}=\frac{\left(1-\theta^{2}\right) M_{i}^{A}\left(\widetilde{p}_{i d}^{A}\right)^{1-\varsigma} d T}{\theta M_{i}^{B}\left(\widetilde{p}_{i d}^{B}\right)^{1-\varsigma}+\left(\theta^{2} \iota^{A}+\iota^{B}\right) M_{i}^{A}\left(\widetilde{p}_{i d}^{A}\right)^{1-\varsigma}} \gtrless 0 \Leftrightarrow d T \gtrless 0,
\end{aligned}
$$

where $\iota^{c}$ is country $c^{\prime}$ s share in world disposable income and $\theta \equiv \tau^{\varsigma^{-1}}$. Inspection of these two equations leads to the following proposition.

Proposition 2. A transfer creates an excess supply (excess demand) for any variety of both goods produced by the donor (recipient). This leads to a deterioration (improvement) of the donor (recipient) terms of trade.

Proof. Expressions (20) and (21).

To understand Proposition 2 consider, for instance, a transfer from $A$ to $B$. The proposition states that the transfer will create an excess demand for any variety produced in $B$ and an excess supply for any variety produced in $A$. The reason is that - for any variety - foreign expenditure is smaller than domestic expenditure since trade cost make the price of the foreign variety higher. Then, although a transfer gives rise to an increase in total expenditure in $B$ equal to the decline in $A$, the difference in the expenditure shares creates an excess supply for all $A$ 's varieties and an excess demand for all $B$ 's varieties. ${ }^{10}$ A direct consequence is that the price of all varieties will decline in the donor country and will increase in the recipient country. This is a deterioration of the donor terms of trade. Proposition 2 shows how moving from the homogeneous good and unitary elasticity to Chamberlin (Dixit-Stiglitz) monopolistic competition gives rise to substantive effects on the terms of trade. Samuelson was right. But there is a lot more than the effect on the terms of trade when

\footnotetext{
8 Samuelson (1954), Table IV (p. 286), cell at the intersection of the row "Basic convention of unitary income elasticity and identical tastes" and the column "Real transport costs"; cell sub-case of elasticity of substitution between goods equal to 1 (Cobb-Douglas).

9 To make the prose lighter I will continue to use the term 'transfer' but since I am using comparative statics it is clear that I am referring to an infinitesimally small transfer. $\mathrm{A}^{\wedge}$ indicates percentage changes.

10 The net effect would be zero in the case of free trade $(\theta=1)$ or in the case of identical Cobb-Doublas preferences between varieties because in such cases the expenditure share on each variety is the same between countries.
} 
factor proportions are in the model. The reason is that the excess demand and supply are in general different for varieties of different goods. This can be seen by using (20) and (21) to compute the ratios $\widehat{D}_{Y}^{c} / \widehat{D}_{Z}^{c}$ and observing that

$$
\begin{aligned}
& \text { If } d T>0 \text {, then } \frac{M_{Y}^{A}}{M_{Z}^{A}} \frac{\left(\widetilde{p}_{Z d}^{B}\right)^{1-\varsigma}}{\left(\widetilde{p}_{Y d}^{B}\right)^{1-\varsigma}} \gtreqless \frac{M_{Y}^{B}}{M_{Z}^{B}} \frac{\left(\widetilde{p}_{Z d}^{A}\right)^{1-\varsigma}}{\left(\widetilde{p}_{Y d}^{A}\right)^{1-\varsigma}} \Rightarrow\left\{\begin{array}{l}
\widehat{D}_{Y}^{A} \\
\widetilde{D}_{Z}^{A} \\
\widetilde{D}_{Y}^{B} \\
\vec{D}_{Z}^{B} \gtreqless 1
\end{array}\right. \\
& \text { If } d T<0 \text {, then } \frac{M_{Y}^{B}}{M_{Z}^{B}} \frac{\left(\widetilde{p}_{Z d}^{A}\right)^{1-\varsigma}}{\left(\widetilde{p}_{Y d}^{A}\right)^{1-\varsigma}} \gtreqless \frac{M_{Y}^{A}}{M_{Z}^{A}} \frac{\left(\widetilde{p}_{Z d}^{B}\right)^{1-\varsigma}}{\left(\widetilde{p}_{Y d}^{B}\right)^{1-\varsigma}} \Rightarrow\left\{\begin{array}{l}
\widehat{D}_{Y}^{A} \\
\widetilde{D}_{Y}^{A} \\
\widehat{D}_{Y}^{B} \\
\widehat{D}_{Z}^{B} \lesseqgtr 1
\end{array}\right.
\end{aligned}
$$

Thus, for instance, the inequalities and implications in (22) tell us that a transfer from $A$ to $B$ (i.e. $T>0$ ) when $A$ has the comparative advantage in $Y$ (as a consequence of which the second inequality holds as $>$ ) causes a smaller excess supply for $Y$ than for $Z$ in $A$ (i.e., $\widehat{D}_{Y}^{A}<0$ and $\widehat{D}_{Z}^{A}<0$ but $\widehat{D}_{Y}^{A} / \widehat{D}_{Z}^{A}<1$ ) and a bigger excess demand for $Y$ than for $Z$ in $B$ (i.e., $\widehat{D}_{Y}^{B}>0$ and $\widehat{D}_{Z}^{B}>0$ but $\left.\widehat{D}_{Y}^{B} / \widehat{D}_{Z}^{B}>1\right)$. Analogously, a transfer from $B$ to $A(T<0)$ when $B$ has the comparative advantage in $Y$ causes $\widehat{D}_{Y}^{A}>0$ and $\widehat{D}_{Z}^{A}>0$ but $\widehat{D}_{Y}^{A} / \widehat{D}_{Z}^{A}>1$ and $\widehat{D}_{Y}^{B}<0$ and $\widehat{D}_{Z}^{B}<0$ but $\widehat{D}_{Y}^{B} / \widehat{D}_{Z}^{B}<1$. All the other cases may be read analogously. A transfer from the skill abundant to the skill scarce country then brings about an increase in the demand for for $Y$ relative to $Z$ in both countries. This will cause an increase in the relative price of $Y$ and in the skill premium via Stolper-Samuelson in both countries. To see the difference with the neoclassical benchmark consider a case where $A$ is $H$-abundant and $Y$ is $H$-intensive. In such case, if we were in the neoclassical benchmark, a transfer from $A$ to $B$ will be neutral whereas in the present model it brings about a deterioration of the terms of trade and an increase in the relative demand for $Y$. One other way to see the difference is that in the neoclassical benchmark the terms of trade and the relative price of the good in which the donor country specialises are identical. In the present model they are not. Thus a deterioration of the terms of trade is compatible with an improvement in the relative price of the good in which the donor country specialises. The inequalities above lead to the following proposition.

Proposition 3. A transfer causes in both countries an increase of the relative demand for the good in which the donor country has the comparative advantage. This has three consequences:

1. An increase in both countries in the relative price of the good in which the donor country has the comparative advantage.

2. An increase in both countries in the relative price of the factor with which the donor country is relatively well endowed.

3. An increase in both countries in the relative mass of varieties of the good in which the donor country has the comparative advantage.

Proof. Direct consequence of (22)-(23).

Product differentiation and comparative advantage are both necessary for Proposition 3. If we remove comparative advantage while keeping monopolistic competition the effects of Proposition 3 vanish and we are left only with Proposition 2, if we remove product differentiation while keeping comparative advantage we are back to Proposition $1 .{ }^{11}$

\subsection{Biased heterogeneity and productivity}

We now resume firm heterogeneity. When firms are heterogeneous in factor intensity and entry is endogenous a transfer affects productivity. To see this it is convenient to use (7) and (8) to write the free entry condition (13) as follows:

$$
\int_{\xi_{i}^{*}}^{\infty}\left\{\left[\frac{m c_{i}^{c}(\xi)}{m c_{i}^{* c}\left(\xi_{i}^{*}\right)}\right]^{1-\varsigma}-1\right\} d G(\xi)=\frac{\digamma_{e}}{\digamma} .
$$

Unbiased heterogeneity means $l(\xi)=h(\xi)$ which implies that factor prices cancel out of (24). In such case, Eq. (24) determines $\xi_{i}^{* c}$ independently of the rest of the model and, in particular, independently of $T$. This implies that a transfer, though it impacts on the price of goods and factors and on the masses, has no impact on productivity. When heterogeneity is biased instead factor prices do not cancel out from the marginal cost ratio. In such situation the free entry condition (24) relates $\xi_{i}^{*}$ to factor prices and, through them, to the transfer. Specificaly, when heterogeneity is biased we have the following relationship:

$$
\frac{d \widehat{\xi_{i}^{* c}}}{d \widehat{\omega^{c}}} \lesseqgtr 0 \Leftrightarrow \beta^{\prime}(\xi) \gtreqless 0 \wedge \sigma \gtreqless 1
$$

where $\omega^{c} \equiv w_{H}^{c} / w_{L}^{c}$ and ${ }^{\wedge}$ represent percentage changes. See Section 7.2 for the mathematical passages. We may state the effect of a transfer on productivity in the following way:

\footnotetext{
${ }^{11}$ In the absence of a comparative advantage $M_{Y}^{A} / M_{Z}^{A}=M_{Y}^{B} / M_{Z}^{B}$ and $\tilde{p}_{Y d}^{A} / \widetilde{p}_{Z d}^{A}=\widetilde{p}_{Y d}^{B} / \tilde{p}_{Z d}^{B}$ therefore the excess demand is identical for all varieties of all goods in the same country as we see by inspection of (22) and (23).
} 
Proposition 4. When factors are gross substitutes, a transfer causes a decline (increase) in average productivity of both industries in both countries if the donor is abundant (scarce) in the factor towards which heterogeneity is biased. When factors are gross complement the relationship is inverted.

Proof. Expression (25)

It is interesting to understand the economic logic of expression (25). Consider, for instance a transfer from $A$ to $B$ when $A$ is $H$-abundant, which gives rise to an increase in the skill premium in both countries (i.e., an increase $\left.\omega^{c}\right)$. Since firms are heterogeneous in skill intensity they are affected differently even when they face the same increase in the skill premium. Specifically, highly skill intensive firms will lose competitiveness with respect to the least skill intensive firms since the former use more intensively the factor whose relative price has increased. Now, if heterogeneity is skill-biased $\left(\beta^{\prime}(t)>0\right)$ and factors are gross substitutes $(\sigma>1)$ then the least skill intensive firms will also be the least productive firms. Their relative position improves and some previously unprofitable firms will become profitable and decide to stay in the market (i.e. $\xi_{i}^{* c}$ declines). Proposition 4 rests on factor proportions and biased heterogeneity; in the absence of either one there is no effect on productivity. ${ }^{12,13}$

\subsection{Welfare effects}

The welfare effects of transfers derive directly from the propositions above. Contrary to the neoclassical benchmark, the donor country bears a secondary burden and the recipient enjoys a secondary benefit. It is easy to understand the reason for these welfare changes. In the donor country all prices and wages fall but part of expenditure goes to foreign varieties whose increase in price causes a reduction in overall purchasing power of donor country residents. Likewise, mutatis mutandi, for the welfare effects of the transfer on the recipient country welfare. For the same reasons all factors bear a secondary burden in the donor country and enjoy a secondary benefit in the recipient country. These welfare changes do not leave world welfare unchanged, however, unless countries have identical factor proportions. The reason is that when factor proportions are not identical a transfer brings about a fall or an increase in productivity in both countries in accordance to Proposition 4 . World welfare declines in the case of a productivity loss and increases in the case of a productivity gain.

\section{Deflation versus depreciation}

In the previous section we reached the conclusion that a transfer involves a reduction in real wages in the donor country. The question I address in this section is how this reduction in real wages is to be achieved: by deflation or by devaluation? The reason for asking this question is that the political feasibility of these two alternatives is very different. To put it in Keynes' words: "If [...] deflation is enforced, how will this help? Only if, by curtailing the activity of business, it throws men out of work, so that, when a sufficient number of millions are out of work, they will then accept the requisite reduction in their money-wages. Whether this is politically and humanly feasible is another matter". Keynes (1929), (p. 7). We have seen the mechanism described by Keynes in the previous sections where the only difference was that the absence of price rigidities made the real wage adjustment instantaneous. An alternative method to reduce real wages "would be to allow the exchange value of the German mark to fall by the amount required to give the necessary bounty to exports and then to resist any agitation to raise money-wages", (Keynes, 1929), (p. 6). Summing up, deflation requires falling nominal wages while depreciation allegedly does not and this makes it politically preferable. The choice between these two alternatives arose also in recent European policy debates where exiting the Euro Area was seen as an alternative to deflation. But is a floating exchange rate really a substitute for deflation? To address this question I switch to the flexible exchange rate regime and resume $e$ as an endogenous variable. Consider the case of a transfer from $A$ to $B$. A fall in the exchange rate diverts demand from $B$ 's to A's varieties thus countering the excess demand for B's varieties and the excess supply of $A$ 's varieties created by the transfer. Will this depreciation eliminate the fall in nominal wage? It will if and only if it can absorb all excess demand and supply generated by the transfer. In such case a transfer has no other effects than the depreciation of the donor country's currency. If instead the depreciation cannot absorb all excess demand and supply then a transfer will have all the effects studied in the previous section including the fall in nominal wages in the donor country. Differentiating Eqs. (14) and (15) with respect to $T$ and $e$ (at $T=0$ and $e=1$ ) we obtain the excess demand generated by the transfer and by the exchange rate change:

$$
\begin{aligned}
\frac{d D_{i}^{A}}{\left(\widetilde{p}_{i d}^{A}\right)^{1-\varsigma}=} & -\frac{\left(1-\theta^{2}\right)\left(\widetilde{p}_{i d}^{B}\right)^{1-\varsigma} M_{i}^{B} \gamma_{i}}{\left(P_{i}^{A}\right)^{1-\varsigma}\left(P_{i}^{B}\right)^{1-\varsigma}} d T \\
& +\left[\frac{\theta \varsigma \gamma_{i} I_{B}}{\left(P_{i}^{B}\right)^{1-\varsigma}}+\left(\frac{\left(\widetilde{p}_{i d}^{B}\right)^{1-\varsigma} M_{i}^{B} I_{A}}{\left(P_{i}^{A}\right)^{2(1-\varsigma)}}-\frac{\theta\left(\widetilde{p}_{i d}^{A}\right)^{1-\varsigma} M_{i}^{A} I_{B}}{\left(P_{i}^{B}\right)^{2(1-\varsigma)}}\right) \theta(\varsigma-1) \gamma_{i}\right] d e
\end{aligned}
$$

\footnotetext{
12 In this model the relative price of a factor relates negatively to its relative abundance (see appendix Section 7.3). Proposition 4, however, does not rest on such relationship. It rests on the effect that a transfer has on relative factor prices and, thereby, on productivity.

${ }^{13}$ Crinò and Epifani (2014) find that larger trade surpluses are associated with lower average skill intensity of exports in skill-abundant countries (p. 521). This evidence is perfectly in line with my theoretical results. Indeed a transfer from the skill abundant country (a larger trade surplus or lower trade deficit) results in a fall in $\xi_{i}^{* c}$ which lowers the skill intensity of exports.
} 


$$
\begin{aligned}
\frac{d D_{i}^{B}}{\left(\widetilde{p}_{i d}^{B}\right)^{1-\varsigma}}= & \frac{\left(1-\theta^{2}\right)\left(\widetilde{p}_{i d}^{A}\right)^{1-\varsigma} M_{i}^{A} \gamma_{i}}{\left(P_{i}^{A}\right)^{1-\varsigma}\left(P_{i}^{B}\right)^{1-\varsigma}} d T \\
& +-\left[\frac{\theta \varsigma \gamma_{i} I_{A}}{\left(P_{i}^{A}\right)^{1-\varsigma}}+\left(\frac{\left(\widetilde{p}_{i d}^{A}\right)^{1-\varsigma} M_{i}^{A} I_{B}}{\left(P_{i}^{B}\right)^{2(1-\varsigma)}}-\frac{\theta\left(\widetilde{p}_{i d}^{B}\right)^{1-\varsigma} M_{i}^{B} I_{A}}{\left(P_{i}^{A}\right)^{2(1-\varsigma)}}\right) \theta(\varsigma-1) \gamma_{i}\right] d e
\end{aligned}
$$

A depreciation that absorbs all excess demand is a de such that $d D_{i}^{c}=0$ for all $i$ and $c$. It is clear by inspection of (26) and (27) that such single de does not exists unless countries have identical factor endowments (proportions and size). If factor proportions are identical then $M_{i}^{A}=M_{i}^{B} \equiv M_{i}, \widetilde{p}_{i d}^{A}=\widetilde{p}_{i d}^{B}, P_{i}^{A}=P_{i}^{B}$, if factor endowments are identical then $I^{A}=I^{B} \equiv I$ and expressions of (26) and (27) collapse to

$$
\begin{aligned}
& \frac{M_{i}}{\gamma_{i}} d D_{i}^{A}=-\frac{(1-\theta)}{(1+\theta)} d T+\frac{\theta[2 \varsigma-(1-\theta)] I}{(1+\theta)^{2}} d e \\
& \frac{M_{i}}{\gamma_{i}} d D_{i}^{B}=\frac{(1-\theta)}{(1+\theta)} d T-\frac{\theta[2 \varsigma-(1-\theta)] I}{(1+\theta)^{2}} d e .
\end{aligned}
$$

In such case a depreciation de equal to the following expression clears all markets:

$$
d e=\frac{\left(1-\theta^{2}\right)}{\theta(2 \varsigma-1+\theta)} \frac{d T_{A B}}{I^{A}}
$$

In this case deflation and depreciation are perfect substitutes. A transfer causes a depreciation of the donor's currency and that is all. Real wages fall but nominal wages are unaffected. Furthermore there are no other effects on the economy: no change in relative prices, no changes in productivity, no changes in world welfare. The transfer repercussions are a zerosum affair mediated by the exchange rate. If, instead, factor proportions are not the same then the excess demand and supply created by the transfer differ for different countries and goods and therefore a depreciation cannot clear all markets. Depreciation of the donor country currency will occur nevertheless but will be accompanied by falling nominal wages in the donor country, increasing nominal wages in the recipient country, and a change in the skill premium in both countries. In such case the currency depreciation does not substitutes for deflation. Thus, the hopes that freely floating exchange rates substitute for deflation are not well-placed.

Proposition 5. Unless countries are identical, depreciation cannot substitute for deflation.

Proof. Inspection of (26) and (27)

\section{Theory with numbers}

We now move to a quantitative exercise where we simulate the effect of the elimination of current account imbalances between the U.S., the Euro-Area, and China. Eliminating current account imbalances implies a transfer from the deficit to the surplus country. To perform such simulation I follow the approach popularised by Dakle, Eaton and Kortum (2007, 2008): I first calibrate the model and then I use the calibrated model to build a counter-factual. Although the approach is the same my model differs grandly from theirs. The quantitative implementation is also different. In particular, they simulate the situation where trade imbalances are eliminated by trade in goods only (leaving a degree of freedom in service trade). I don't allow for that. Moreover, they allow for bilateral trade imbalances to remain while I simulate the situation in which all bilateral imbalances are zeroed. Two other papers (cited below) simulate the effect of transfers but their approach is different in that they perform a direct simulation without calibrating the model. Parameter values, however, are conscientiously taken from the data or from the empirical literature. Although the approach in these papers is less demanding on the model the results are informative and constitute a prima facie evaluation of the effect of transfers. Along these lines (Epifani and Gancia, 2017) perform numerical simulations based on a one factor model containing a non-traded good and intermediated inputs. They simulate the effect of a trade surplus on the donor country (a transfer from China or Germany in their simulations) but leave unexplored the issue of eliminating trade imbalances for the other countries. Corsetti et al. (2013) perform a simulation in an inter-temporal model. They simulate the effect of current account imbalances generated by inter-temporal shock to demand, to supply, or by imperfect foresight.

For my exercise I need to parametrise the model and to match data. I assign to $\sigma$ the value of 2 and 3 as often found in gravity equations (see Head and Mayer, 2006, for an extensive discussion). I assume that $G(\xi)$ is Pareto and take the shape parameter value from Bernard et al. (2003) who find it to be 3.7. ${ }^{14}$ Following a consolidated practice I define skilled workers as workers with tertiary education (see, e.g., Romalis, 2004; Costinot and Vogel, 2010). The relative abundance of skilled labour is measured by the educational attainment reported in Barro and Lee (2013) and I assign values to $v_{j}^{c}$ accordingly..$^{15}$ The technology parameters are $\lambda_{Y}=4 / 10$ and $\lambda_{Z}=6 / 10$, which make $Y$ skill intensive and match the data

\footnotetext{
14 The model in this paper gives rise to a gravity equation whose trade elasticity is $\sigma-1$. Thus, as in Crinò and Epifani (2014) I can assign to $\sigma$ and to the shape parameter the values found in the gravity literature.

${ }^{15}$ For the Euro Area the skill abundance is computed as the average weighted by GDP.
} 
Table 1

GDP and skill abundance.

\begin{tabular}{llll}
\hline & United States & Euro Area & China \\
\hline GDP share & 0.45 & 0.29 & 0.26 \\
Skill abundance & 0.268 & 0.1224 & 0.027 \\
\hline
\end{tabular}

Table 2

Trade imbalances.

\begin{tabular}{llll}
\hline & United States & Euro Area & China \\
\hline United States & & -0.55 & -1.4 \\
Euro Area & & -0.67 \\
\hline
\end{tabular}

Table 3

Simulation results.

\begin{tabular}{llcc}
\hline \multicolumn{4}{l}{ Eliminating bilateral trade imbalances } \\
\hline \multicolumn{4}{l}{ All figures in percentage changes } \\
\hline & United States & Euro Area & China \\
\hline Average productivity in $Y$ & -0.0057 & -0.0019 & -0.0076 \\
Average productivity in $Z$ & -0.0110 & -0.0037 & -0.0148 \\
Secondary benefit for $H$ & -0.0618 & 0.0308 & 0.1504 \\
Secondary benefit for $L$ & -0.0974 & 0.0177 & 0.1012 \\
Secondary benefit for the country & -0.0807 & 0.0209 & 0.1040 \\
Nominal Exchange Rate of USD & - & 0.099 & 0.179 \\
\multicolumn{4}{c}{ The neoclassical benchmark predicts no changes } \\
\hline
\end{tabular}

reported in Romalis (2004, Table 2), for the manufacturing sector. I assign to $\tau$ the value of 0.8 and 0.6 which corresponds to a trade costs of $25 \%$ and $67 \%$ of value shipped. The expenditure share $\gamma_{Y}$ is set at 0.3 . Other parameter values are $F=2$ and $F_{e}=0.05$.

I calibrate the model to match GDP shares and bilateral trade imbalances in percentage of GDP. The data source for these values is the World Bank. I use the calibrated model to simulate the elimination of all bilateral trade imbalances. Tables 1 and 2 report data on GDP shares, skill abundance, and trade surpluses. The two tables combined show that eliminating trade imbalances requires transfers from skill abundance to skill scarce countries.

Table 3 shows the simulation results. The table reports the results for $\sigma=2$ and $\tau=0.8$. Simulations using the other combinations of parameter values gave results in the same order of magnitude. Average productivity declines in all countries and industries in line with Proposition 4. All factors bear a secondary burden in the donor country and enjoy a secondary benefit in the recipient country in line with Proposition 3. Moreover, $H$ is hurt less than $L$ in the donor-skillabundant country (U.S.) and benefits more than $L$ in the two recipient-skill-scarce countries (Euro Area and China) in line with Proposition 3.

I conclude this section with a simple comparison. Trade agreements and trade imbalances often 'compete' for space in the news. So, how important are these figures compared to those of trade agreements? A recent study by Caliendo and Parro (2015) estimated that as a consequence of NAFTA the cumulated welfare increase for the U.S. over the period 1993-2005 was of $0.08 \%$. This is almost exactly equal to the simulated welfare loss from eliminating all trade imbalances reported in Table 3. If the U.S. trade deficit keeps the current trend this welfare loss may happen in only a couple of years. Although this is only a rough comparison it tells us that the welfare consequences of trade imbalances may be as large as those of major trade agreements.

\section{Summary and conclusion}

This paper revisits the transfer problem in the light of models featuring monopolistic competition and biased heterogeneity. I have found results that are very different from those in the previous literature and I have explored issues never discussed before in the context of the transfer problem.

The first set of results show the synergy between biased heterogeneity and factor proportions in giving rise to the effects of transfers on specialisation, on factor prices, and on productivity. The second set of results concerns the consequences of a transfer on country welfare, factor welfare, world welfare, and on inequality. The third set of results concerns the comparison between deflation and depreciation. The last set of results shows that he magnitude of the secondary effects arising from closing up current trade imbalances is comparable to the welfare effects arising from major trade agreements. 


\section{Appendix}

\section{A1. Transfers in the neoclassical benchmark}

Recall that in the neoclassical benchmark $Y$ and $Z$ are homogeneous goods, firms are homogenous, and there is perfect competition. To fix ideas, and without loss of generality, assume that factor intensities and factor proportions are such that country $A$ is the exporter of $Y$. To avoid notational confusion let $\mathfrak{p}_{i c}$ be the price of good $i$ in country $c$ in the neoclassical model. Transport costs and the export pattern imply the following price relationships:

$$
\mathfrak{p}_{Y B}=\frac{1}{\tau} \mathfrak{p}_{Y A}, \quad \mathfrak{p}_{Z A}=\frac{1}{\tau} \mathfrak{p}_{Z B},
$$

The general equilibrium system is composed of the following nine equations:

$$
\begin{aligned}
& \frac{\left(Y_{A}+Y_{B} / \tau\right) \mathfrak{p}_{Y A}}{\left(Y_{A}+\frac{Y_{B}}{\tau}\right) \mathfrak{p}_{Y A}+\left(\frac{Z_{A}}{\tau}+Y_{B}\right) \mathfrak{p}_{Z B}}=\frac{\gamma_{Y}\left(I_{A}-T\right)-\gamma_{Y}\left(I_{B}+T\right)}{I_{A}+I_{B}} \\
& \mathfrak{p}_{i c}=m c_{i}^{c}, \quad i=Y, Z ; \quad c=A, B . \\
& \frac{\partial m c_{Y}^{c}}{\partial w_{L}^{c}} Y_{c}+\frac{\partial m c_{Z}^{c}}{\partial w_{L}^{c}} Z_{c}=v_{L}^{c} \underline{L}, \quad c=A, B . \\
& \frac{\partial m c_{Y}^{c}}{\partial w_{H}^{c}} Y_{c}+\frac{\partial m c_{Z}^{c}}{\partial w_{H}^{c}} Z_{c}=v_{H}^{c} \underline{H}, \quad c=A, B .
\end{aligned}
$$

Eq. (32) ensures goods market clearing, Eq. (33) results from profit maximisation, Eqs. (34) and (35) ensure equilibrium in factor market. This system and the choice of a numéraire determine the ten endogenous variables: four factor prices $\left\{w_{j}^{c}\right\}$, two commodity prices $\left\{\mathfrak{p}_{Y A}, \mathfrak{p}_{Z B}\right\}$, and four output quantities $\left\{Y_{c}, Z_{c}\right\}$. The important thing to notice is that the two $T$ representing the transfer cancel each other out, see Eq. (32). Thus, the transfer has no impact on any endogenous variable. The crucial assumptions for this result are identical preferences and unitary elasticity of substitution between goods. This is the Samuelson neutrality proposition and our benchmark.

If the elasticity of substitution between goods is not unity then a transfer is not neutral and does not cancel out from the right-hand side of (32) because the expenditure shares would differ between countries. As an example, replace the CobbDoublas with a CES and an elasticity of substitution between goods denoted $\varsigma_{Y Z}$. Then the market clearing condition take the same form as (32) but two distinct expenditure shares $\gamma_{Y A}$ and $\gamma_{Y B}$ replace the common expanditure share $\gamma_{Y}$ :

$$
\frac{\left(Y_{A}+Y_{B} / \tau\right) \mathfrak{p}_{Y A}}{\left(Y_{A}+\frac{Y_{B}}{\tau}\right) \mathfrak{p}_{Y A}+\left(\frac{Z_{A}}{\tau}+Y_{B}\right) \mathfrak{p}_{Z B}}=\frac{\gamma_{Y A}\left(I_{A}-T\right)-\gamma_{Y B}\left(I_{B}+T\right)}{I_{A}+I_{B}}
$$

where

$$
\begin{aligned}
\gamma_{Y A} & =\frac{\mathfrak{p}_{Y A}^{1-\varsigma_{Y Z}}}{\mathfrak{p}_{Y A}^{1-\zeta_{Y Z}}+\tau \varsigma_{Y Z}^{-1} \mathfrak{p}_{Z B}^{1-\zeta_{Y Z}}} \\
\gamma_{Y B} & =\frac{\tau \varsigma_{Y Z}^{-1} \mathfrak{p}_{Y A}^{1-\zeta_{Y Z}}}{\tau \varsigma_{Y Z}-1 \mathfrak{p}_{Y A}^{1-\zeta_{Y Z}}+\mathfrak{p}_{Z B}^{1-\zeta_{Y Z}}}
\end{aligned}
$$

Trade costs make that consumers do not face the same price in different countries and the CES makes that the expenditure share is sensitive to such price difference. Then, as stated by Samuelson, the transfer is not neutral. There will be excess demand and supply, which will require a terms of trade adjustment, the direction of which depends on whether $\varsigma_{Y Z}$ is larger or smaller than one. In a mode with fixed output the terms of trade will do the job of eliminating the excess demand, in a model with flexible output the output response comes to attenuate the terms of trade response but does not eliminate it (Samuelson 1954, Table IV and discussion in pp. 286-287).

\section{A2. Mathematical passages for inequality (25)}

Total differentiation of the free entry condition (24) gives

$$
0=\underbrace{\left\{(1-\varsigma) \Lambda_{i}^{\sigma} \omega^{1-\sigma} \int_{\xi_{i}^{*}}^{\infty} \frac{\left(h_{i} / h_{i}^{*}\right)^{\sigma-1}-\left(l_{i} / l_{i}^{*}\right)^{\sigma-1}}{\left[\omega^{1-\sigma} / h_{i}^{* \sigma-1}+\Lambda_{i}^{\sigma} / l_{i}^{* \sigma-1}\right]^{2}} d G\right\}}_{\Upsilon_{i, \omega}^{c}} \hat{\omega}
$$




$$
+\underbrace{\left\{(1-\varsigma)\left(\frac{l_{i}^{* \sigma-1}}{\omega^{\sigma-1}} \varepsilon_{a_{i}^{*}}+\Lambda_{i}^{\sigma} h_{i}^{* \sigma-1} \varepsilon_{b_{i}^{*}}\right) \int_{\xi_{i}^{*}}^{\infty} \frac{\frac{l_{i}^{\sigma-1}}{\omega^{\sigma-1}}+\Lambda_{i}^{\sigma} h_{i}^{\sigma-1}}{\left[\frac{l_{i}^{* \sigma-1}}{\omega^{\sigma-1}}+\Lambda_{i}^{\sigma} h_{i}^{* \sigma-1}\right]^{2}} d G\right\}}_{\Upsilon_{i, \xi_{i}^{*}}^{c}} \widehat{\xi_{i}^{*}}
$$

where $\varepsilon_{l_{i}} \equiv l_{i}^{\prime}(\xi) \xi / l_{i}(\xi)$, where $\varepsilon_{h_{i}} \equiv h_{i}^{\prime}(\xi) \xi / b_{i}(\xi)$, and where $\Lambda_{i} \equiv\left(1-\lambda_{i}\right) / \lambda_{i}$ The signs of $\Upsilon_{i, \xi_{i}^{*}}^{c}$ and $\Upsilon_{i, \omega}^{c}$ are

$$
\begin{aligned}
& \Upsilon_{i, \omega}^{c} \lesseqgtr 0 \Leftrightarrow \beta^{\prime}(\xi) \gtreqless 0 \wedge \sigma \gtreqless 1 \\
& \Upsilon_{i, \xi_{i}^{*}}^{c}<0
\end{aligned}
$$

From which (25) follows directly.

\section{A3. Factor proportions and relative factor prices}

In this model the relative price of a factor relates negatively to its relative abundance in costly trade. In our notation this is written as follows:

$$
\omega^{A} \gtrless \omega^{B} \Leftrightarrow v_{H}^{A} \gtrless v_{L}^{A} \quad \forall \tau \in(0,1) .
$$

While total differentiation shows this unequivocally it nicer to show that this is indeed the case by the following thought experiment. Assume that factors price equalised in costly trade. Then, from (39) and its derivatives we have $\beta_{i}^{* A}=\beta_{i}^{* B}, \forall i$. Therefore,

$$
m c_{i}^{* A}=m c_{i}^{* B} \Rightarrow \widetilde{m c} c_{i}^{A}=\widetilde{m} c_{i}^{B} \Rightarrow \widetilde{p}_{d i}^{A}=\widetilde{p}_{d i}^{B}
$$

Under factors price equalisation goods markets equilibrium equations (14) and (15) become

$$
\begin{aligned}
& {\left[\frac{\widetilde{m} c_{i}^{A}}{m c_{i}^{* A}}\right]^{1-\varsigma} \varsigma F_{i} \widetilde{m c_{i}^{A}}=\frac{\gamma_{i} A^{A}}{M_{i}^{A}+\tau^{\sigma-1} M_{i}^{B}}+\frac{\tau^{\sigma-1} \gamma_{i} I^{B}}{\tau^{\sigma-1} M_{i}^{A}+M_{i}^{B}}, \quad \forall i} \\
& {\left[\frac{\widetilde{m} c_{i}^{B}}{m c_{i}^{* B}}\right]^{1-\varsigma} \varsigma F_{i} \widetilde{m c} B=\frac{\tau^{\sigma-1} \gamma_{i}{ }^{A}}{M_{i}^{A}+\tau^{\sigma-1} M_{i}^{B}}+\frac{\gamma_{i} I^{B}}{\tau^{\sigma-1} M_{i}^{A}+M_{i}^{B}}, \quad \forall i}
\end{aligned}
$$

Let $\widetilde{L}_{i}^{c}$ and $\widetilde{H}_{i}^{c}$ be average factors demand in each country and industry. As we know they obtain by applying Shepherd's lemma to the cost function. Under factors price equalisation equalities (43) hold, therefore $\widetilde{L}_{i}^{A}=\widetilde{L}_{i}^{B}=\widetilde{L}_{i}$ and $\widetilde{H}_{i}^{A}=\widetilde{H}_{i}^{B}=\widetilde{H}_{i}$ and equilibrium in factors markets is

$$
\begin{array}{ll}
\left(\widetilde{L}_{Y} M_{Y}^{c}+\widetilde{L}_{Z} M_{Z}^{c}\right)=v_{L}^{c} \bar{L} ; & c=A, B . \\
\left(\widetilde{H}_{Y} M_{Y}^{c}+\widetilde{H}_{Z} M_{Z}^{c}\right)=v_{H}^{c} \bar{H} ; & c=A, B .
\end{array}
$$

Using (43) in Eqs. (44) and (45) and solving gives $M_{Y}^{A} / M_{Z}^{A}=M_{Y}^{B} / M_{Z}^{B}$. This solution in the goods market equilibrium is inconsistent with equilibrium in the factors market. Indeed, $M_{Y}^{A} / M_{Z}^{A}=M_{Y}^{B} / M_{Z}^{B}$ implies from (46) and (47) that the relative demand for $L$ is the same in both countries, but relative supply is not. Therefore, $\omega^{A}=\omega^{B}$ is inconsistent with equilibrium in all markets. In which direction should factors price move to assure equilibrium in all markets? This is easily answered by observing from (46) and (47) that under factor price equalisation relative demand for $L$ falls short of relative supply in $B$ and exceeds relative supply in $A$. Therefore $\omega^{A} / \omega^{B}$ must increase. This will make all industries become more $H$-intensive in $A$ and less $H$-intensive in $B$ thus pushing towards the equilibrium in factors markets. Naturally, a change in factors price alone is not sufficient to assure equilibrium, as a matter of facts an increase in $\omega^{A} / \omega^{B}$ pushes marginal costs in different directions and requires $M_{Y}^{A} / M_{Z}^{A}>M_{Y}^{B} / M_{Z}^{B}$ for the goods market equilibrium to be satisfied. Thus, a costly trade equilibrium is necessarily one in which $\omega^{A}>\omega^{B}$ and $M_{Y}^{A} / M_{Z}^{A}>M_{Y}^{B} / M_{Z}^{B}$, which is the canonical Heckscher-Ohlin outcome and it occurs in our model for exactly the same reasons as in Heckscher-Ohlin. After all, this is intuitive since our model structure does not violate any of the key assumptions of the Heckscher-Ohlin model.

\section{Supplementary material}

Supplementary material associated with this article can be found, in the online version, at doi:10.1016/j.euroecorev.2018. 07.007 . 


\section{References}

Balasko, Y., 1978. The transfer problem and the theory of regular economies. Int. Econ. Rev. 19 (3), $687-694$.

Barro, R., Lee, J., 2013. A new data set of educational attainment in the world. J. Dev. Econ. 104 (4). $1950-2010$.

Bernard, Andrew, B., Jonathan Eaton, J., Jensen, B., Kortum, S., 2003. Plants and productivity in international trade. Am. Econ. Rev. 93, $1268-1290$.

Bernard, A.B., Redding, S.J., Schott, P.K., 2007. Comparative advantage and heterogenous firms. Rev. Econ. Stud. 74, 31-66.

Brakman, S., van Marrewijk, C., 1995. Transfers, returns to scale, tied aid and monopolistic competition. J. Dev. Econ. 47, $333-354$.

Burstein, A., Jonathan, V., 2016. International trade, technology, and the skill premium, Forthcoming in the J. Polit. Econ.

Caliendo, L., Parro, F., 2015. Estimates of the trade and welfare effects of NAFTA. Rev. Econ. Stud. 82 (1), 1-44.

Corsetti, G.C., Martin, P., Pesenti, P., 2013. Varieties and the transfer problem. J. Int. Econ. 89, 1-12.

Costinot, A., Vogel, J., 2010. Matching and inequality in the world economy. J. Polit. Econ. 118 (4), 747-786.

Crinò, R., Epifani, P., 2014. Trade imbalances, export structure and wage inequality. Econ. J. 124 (May), $507-539$.

Crozet, M., Trionfetti, F., 2013. Firm-level comparative advantage. J. Int. Econ. 91, 321-328.

Davis, D., 1998. The home market effect: trade and industrial structure. Am. Econ. Rev. 88 (5), 1264-1276.

Devereux, M.B., Smith, G.W., 2007. Transfer problem dynamics: macroeconomics of the Franco-Prussian war indemnity. J. Monet. Econ. 54 (8), $2375-2398$.

Dixit, A., 1983. The multi-country transfer problem. Econ. Lett. 13 (1), 49-53.

Djajić, S., Lahiri, S., Raimondos-Møller, P., 1999. Foreign aid, domestic investment and welfare. Econ. J. 109, 698-707.

Dornbusch, R., Fischer, S., Samuelson, P., 1977a. Comparative advantage, trade, and payment in a Ricardian model with a continuum of goods. Am. Econ. Rev. 67 (5), 823-839.

Dornbusch, R., Fischer, S., Samuelson, P., 1977b. Heckscher-ohlin trade theory with a continuum of goods. Am. Econ. Rev. 67 (5), $823-839$.

Eaton, J., Kortum, S., 2002. Technology, geography, and trade. Econometrica 70 (5), 1741-1779.

Epifani, P., Gancia, G., 2017. Global imbalances revisited: The transfer problem and transport costs in monopolistic competition. J. Int. Econ. 108, 99-116.

Galor, O., Polemarchakis, H.M., 1987. Intertemporal equilibrium and the transfer paradox. Rev. Econ. Stud. LIV, 147-156.

Head, K., Mayer, T., 2006. Regional wage and employment responses to market potential in the EU. Reg. Sci. Urban Econ. 36, $573-594$.

Johnson Harry, G., 1956. The transfer problem and exchange stability. J. Polit. Econ. 64 (3), 212-225.

Jones, R.W., 1970. The transfer problem revisited. Economica 37 (146), 178-184.

Jones, R.W., 1975. Presumption and the transfer problem. J. Int. Econ. 5, 263-274.

Keynes, J.M., 1929. The german transfer problem. Econ. J. 39 (153), 1-7.

Krugman, P., Venables, A., 1995. Globalization and the inequality of nations. Q. J. Econ. 110, 857-880.

Lane, P.R., Milesi-Ferretti, G.M., 2004. The transfer problem revisited: net foreign assets and real exchange rates. Rev. Econ. Stud. 86 (4), $841-857$.

McDougall, I.A., 1965. Non-traded goods and the transfer problem. Rev. Econ. Stud. 32 (1), 67-84.

Melitz, M.J., 2003. The impact of trade on intra-industry reallocations and aggregate industry productivity. Econometrica 71 (6), $1695-1725$.

Metzler, L.A., 1942. The transfer problem reconsidered. J. Polit. Econ. 50 (3), 397-414.

Metzler, L.A., 1951. A multi-country theory of income transfers. J. Polit. Econ. 59, 14-29.

Mundell, R., 1960. The pure theory of international trade. Am. Econ. Rev. 50 (1), 67-110.

Ohlin, B., 1929. The reparation problem: a discussion. Econ. J. 39 (154), 172-182.

Picard, P.M., Worrall, T., 2015. Currency Areas and Voluntary Transfers, CREA Discussion Paper Series 15-12, Center for Research in Economic Analysis, University of Luxembourg. Forthcoming in JIE.

Pigou, A.C., 1932. The effect of reparations on the real ratio of international interchange. Econ. J. 42, 532-543.

Romalis, J., 2004. Factor proportions and the structure of commodity trade. Am. Econ. Rev. 94 (1), 67-97.

Rueff, J., 1929. Mr. keynes' views on the transfer problem. Econ. J. 39 (155), 388-408.

Samuelson, P., 1952. The transfer problem and transport costs: The terms fo trade when impediments are absent. Econ. J. 62 (246), $278-304$.

Samuelson, P., 1954. The transfer problem and transport costs II: Analysis of effects of trade impediments. Econ. J. 64 (254), $264-289$.

Yano, M., 1983. Welfare aspects of the transfer problem. J. Int. Econ. 15 (3-4), 277-289.

Yeaple, S.R., 2005. A simple model of firm heterogeneity, international trade, and wages. J. Int. Econ. 65, 1-20. 